\title{
Climate change influences on pollinator, forest, and farm interactions across a climate gradient
}

\author{
Lee Hannah $^{1} \cdot$ Marc Steele $^{2} \cdot$ Emily Fung $^{3}$ • \\ Pablo Imbach ${ }^{4} \cdot$ Lorriane Flint $^{5}$ - Alan Flint ${ }^{5}$
}

Received: 19 November 2015 / Accepted: 2 December 2016 /Published online: 20 December 2016

(C) The Author(s) 2016. This article is published with open access at Springerlink.com

\begin{abstract}
Climate impact models are often implemented at horizontal resolutions ("scales") too coarse to be readily applied in local impact assessments. However, recent advancements in fine-scale modeling are allowing the creation of impact models that can be applied to landscape-scale adaptation planning. Here, we illustrate the use of fine-scale impact models for landscape-scale adaptation planning of pollination services for six sites in Central America. The strategies include the identification of (1) potential reservoir areas that may retain bee diversity and serve as a source of recolonization after climate shocks such as droughts; and (2) potential restoration areas, where improving forest cover is likely to lead to increases in pollinator services both in the present and in the future. Coarse-scale $(>1-\mathrm{km}$ horizontal resolution) climatic controls on pollinator diversity and forest cover determine the general location of these areas in our six landscapes. Fine-scale $(<100-\mathrm{m}$ horizontal resolution) variation in climatic water deficit provides an index of forest health which can help identify intervention strategies within these zones. All sites have significant areas in which protecting
\end{abstract}

This article is part of a Special Issue on "Climate change impacts on ecosystems, agriculture and smallholder farmers in Central America” edited by Camila I. Donatti and Lee Hannah.

Electronic supplementary material The online version of this article (doi:10.1007/s10584-016-1868-x) contains supplementary material, which is available to authorized users.

Lee Hannah

lhannah@conservation.org

1 Betty and Gordon Moore Center for Science, Conservation International, University of California, Santa Barbara, Arlington, VA 22202, USA

2 Bren School of Environmental Science \& Management, 2400 Bren Hall, University of California, Santa Barbara, Santa Barbara, CA 93160, USA

3 Tropical Agricultural Research and Higher Education Center (CATIE), Turrialba, Cartago 30501, Costa Rica

4 Environmental Modeling Laboratory, Climate Change Program, Tropical Agricultural Research and Higher Education Center (CATIE), Turrialba, Cartago 30501, Costa Rica

5 United States Geological Survey, Placer Hall, 6000 J Street, Sacramento, CA 95819, USA 
or restoring forest cover is likely to enhance pollination services. The gradient in rainfall change across the study sites dictates choice of adaptation strategies.

\section{Introduction}

Climate change is altering natural and human systems, and interactions between the two (Rosenzweig and Parry 1994; Root et al. 2003; Turner et al. 2010). Agricultural suitability is changing, with important consequences for production and conservation (Hannah et al. 2013), while at the same time species and ecosystems are moving to track suitable climatic conditions (Parmesan and Yohe 2003). Interactions between production systems and nature, such as those involved in pollination services, depend on dynamics at landscape scales as well as on climatic effects that are exerted on regional scales (Hanson et al. 2012). Effective adaptation actions should incorporate consideration of both regional and fine-scale controls.

Combining coarse- $(>1 \mathrm{~km})$ and fine-scale $(<1 \mathrm{~km})$ simulations allows elaboration of climate change adaptation strategies at landscape scales (Flint and Flint 2012). For instance, the combination of coarse-scale modeling of climatic controls on species distributions can be combined with fine-scale modeling of factors, such as forest health, which determine local habitat suitability for species providing ecosystem services (Pearson and Dawson 2003).

Pollination is a good test case for using modeling at multiple scales, because the distributions of pollinating species are determined by climate at coarse scales (extent of occurrence), but individual pollinator species are dependent on adequate natural habitat to maintain viable populations at fine scales (area of occupancy) (Kremen et al. 2007). Climate change disrupts and rearranges pollination services by changing pollinator distributions over broad areas and by influencing the health of habitats, such as forests, which pollinators depend on at local scales (Potts et al. 2010; Memmott et al. 2007).

Climatic water deficit (CWD; Stephenson 1998), the difference between evaporative demand and available water, can be a useful index of health of pollinator habitat, since it is used as an index of likely mortality in tropical forests during drought and has been linked to tree mortality in longitudinal studies (Condit et al. 1995; Lewis et al. 2011; McIntyre et al. 2015). The effect of healthy forests on crop productivity, mediated by native forest pollinators, make these fine-scale CWD variations important to climate change adaptation efforts for both people and nature.

Globally, native forest pollinators are important in production of major commodity and subsistence crops including coffee, beans, chilis, and many other crops, particularly in diverse landscapes dominated by smallholder farmers (Klein et al. 2007). Increasing pollinator services are realized with increasing native habitats in proximity to agricultural fields (Garibaldi et al. 2011). As a result, the fate of fine-scale interactions between smallholders, forests, and native forest pollinators has global repercussions for smallholder production.

Maintaining forest cover to foster populations of native forest pollinators has been shown to improve yields in smallholder crops by as much as $20 \%$ in Central America (Ricketts et al. 2004; Garibaldi et al. 2013). Native bee pollinators are less relevant in large monocultures, because the spatial extent of the monoculture may be larger than the foraging distance of native pollinators (Ricketts et al. 2008; Ricketts 2004; Koh et al. 2016). Native bee pollinators benefit monocultures only at the periphery near forests, while the heterogeneous landscapes typical of 
smallholder production may allow crops to be near forest or shade cropping areas that provide habitat for native forest pollinators (Kennedy et al. 2013; Garibaldi et al. 2014).

Landscape adaptation strategies to maintain native forest pollination services will play an important role in maintaining global agricultural productivity as climate changes. They will be important in Central America, particularly for coffee production and smallholder agriculture because coffee production is an important economic activity in this region and smallholder farmers are responsible for a significant portion of the region's production (FAO 2015; Berdegué and Fuentealba 2011). These adaptation strategies need to respond to both coarseand fine-scale effects of climate change - coarse-scale climatic controls on native forest pollinator species richness and distribution, and fine-scale climate change effects on native forest health that affect survivorship of native forest pollinator populations. In concert with information about these coarse- and fine-scale effects of climate change, protecting and restoring native habitats are important adaptation actions that can improve pollination services, both now and in the future. Coarse-scale (1-5 km) models of future pollinator richness can determine locations that can provide high-diversity reservoirs of pollinators. Fine-scale (100$500 \mathrm{~m}$ ) models of forest cover and CWD can inform how and where to restore native habitats by providing information on expected forest habitat health as climate changes.

Here, we explore options for adaptation to the impacts of climate change on native forest bee pollinators in Central America, a region in which smallholders generally comprise the largest portion of the agricultural sector (Berdegué and Fuentealba 2011). We use six focal sites in three countries (Table S1) in which the dominant native vegetation is tropical forest. The sites were chosen to be important coffee-growing locations in which the presence of native forest bee pollinators would enhance yield. The sites represent a gradient of projected climate change (high N - S low) and an opposing gradient in remaining forest cover (low N - S high).

We test two principles - restoration areas and reservoir areas as the basis for adaptation at the six sites. Restoration areas are locations in which restoring forest cover will improve bee pollination services. Reservoir areas are locations with high forest cover and high future bee diversity that can serve as a source of repopulation of pollinators after climatic events such as drought. We use coarse-scale $(1 \mathrm{~km})$ models to estimate native bee diversity, and fine-scale $(250 \mathrm{~m})$ models of CWD to estimate future habitat health under climate change.

\section{Methods}

We modeled bee diversity and forest health change to define three types of adaptation strategy in six study landscapes. The adaptation strategies were based on the assumption that climate determins pollinator distribution at broad scales (modeled at $1 \mathrm{~km}$ ), while locations of individual pollinator populations are determined by habitat quality, as indicated by forest health.

The adaptation strategies are: protecting reservoirs of pollination services; restoring pollinator services; and restoring reservoirs. Potential reservoir areas were defined by high modeled future bee diversity under six GCM scenarios and high current forest cover ( $>90 \%$ ) from satellite data. Restoration areas were defined by future forest bee habitat health determined by modeled future climatic water deficit (CWD) and proportion of forest in the landscape. Reservoir restoration was suggested where future bee diversity is high, future forest health is high, and existing forest areas are limited. Details of bee species modeling, forest health (CWD) modeling, and forest cover analysis are presented below. 


\subsection{Study landscapes}

Six landscapes in Central America were selected for study, based on the presence of tropical forest habitat types suitable for supporting native bee pollinators, the presence of smallholder coffee cultivation capable of benefitting from native pollinators, forest cover in excess of $20 \%$, and the presence of one or more protected areas. Two sites were selected each in Guatemala, Honduras, and Costa Rica (see figure insets for locations). Each study site was $60 \times 60 \mathrm{~km}$.

\subsection{Climate datasets and downscaling}

Datasets used for historical climate were the WorldClim average annual monthly dataset (Hijmans et al. 2005; http://www.WorldClim.org) at 1000-m spatial resolution (monthly precipitation and air temperature) for pollinator models. For forest health (CWD) models, the Climatic Research Unit (CRU 3.1; http://www.cru.uea.ac.uk/data) transient monthly dataset (1950-2009; precipitation, air temperature, and potential evapotranspiration (PET)), at approximately a 40,000-m spatial resolution were used because of their higher temporal resolution, downscaled to $250 \mathrm{~m}$ using WorldClim, and digital elevation model (DEM) data.

Six global climate models were selected from the World Climate Research Programme (WCRP) Coupled Model Intercomparison Project phase 5 (CMIP5) on the basis of the IPCC 5th Assessment Report: MIROC-ESM (MR), MIROC_ESM-CHEM (MI), GFDL-CM3 (GF), CNRM-CM5 (CN), NorESM1-M (NO), and CCSM4 (CC) for two representative concentration pathways (RCP4.5 and RCP8.5). For pollinator models, climate projections from the WorldClim dataset (http://www.ccafs.cgiar.org/blog/tags/worldclim-dataset) were used at 1000-m spatial resolution as monthly averages for 30-year periods, 2041-2070 (2050 average), and 2071-2100 (2080 average). For climatic water deficit (forest health) models, downscaling was done according to Flint and Flint (2012) then scaled to the more spatially detailed WorldClim data for every month to provide more topographically accurate representations of the climate. The 1000 grids were then spatially downscaled to $250 \mathrm{~m}$ using a digital elevation model (DEM).

\subsection{Pollinator models}

Natural range distribution information and occurrence points of 38 native species distributed in Latin America were compiled from different collections and existing literature: Global Biodiversity Information Facility (GBIF 2001), Instituto Nacional de Biodiversidad (Atta-INbio 2001), and the Bee Database Project from the American Museum of Natural History (2013). In addition, David Roubik, a neotropical bee specialist, was consulted for information on the bee species which are better suited to offer pollination services for coffee crops.

To model the potential distribution of the 38 species, Maxent version 3.3k (Phillips et al. 2006) was used, employing 19 bioclimatic variables as predictors to estimate species range distributions. The spatial extent of the variables extended from Mexico through the entirety of South America.

Model agreement for future bee species richness is the aggregate of six GCM scenarios in five categories: (1) 1-5 spp., (2) 5-10 spp., (3) 10-15 spp., (4) 15-20 spp., and (5) >20 spp. For $80 \%$ model agreement in the $>25$ spp. range, at least five models must agree that the anticipated number of bee species present are greater than 20. Model agreement for the relative percent change for species richness is the aggregate of the relative percent change for each of 
the six GCM scenarios. Each relative percent change is the difference between the current species richness dataset and the species richness under any given GCM scenario.

\subsection{Forest health models}

Forest health was simulated using climatic water deficit (CWD) at $250 \mathrm{~m}$ using the Basin Characterization Model (BCM). Tropical forests are sensitive to length and presence of dry season. We used CWD in dry season to simulate future forest health. For each site, the month of highest observable CWD was selected for each GCM to represent the peak in dry season (Underwood et al. 2014). Change in monthly average CWD was found by taking the difference between the selected future CWD dataset and the corresponding current monthly average CWD values.

GCM model agreement for CWD change was found by aggregating the six models according to five categories: change in CWD (1) $\geq 25 \mathrm{~mm}$, (2) $18-25 \mathrm{~mm}$, (3) $12.5-18 \mathrm{~mm}$, (4) $0-12.5 \mathrm{~mm}$, and (5) $\leq 0 \mathrm{~mm}$. For $80 \%$ model agreement in the $\geq 25 \mathrm{~mm}$ range, at least five models must agree that the expected change in CWD will be greater than or equal to $25 \mathrm{~mm}$. Similarily, for $50 \%$ model agreement, at least three models must agree.

The Basin Characterization Model (BCM) is a regional water balance model that has been applied to a number of watersheds in California (Flint et al. 2013, 2015; Ackerly et al. 2015) and other regions (Flint and Flint 2012) at a 250-m grid scale. The BCM mechanistically models the pathways of precipitation into evapotranspiration, infiltration into soils, runoff, or percolation below the root zone to recharge groundwater. The evapotranspiration component is derived through the use of PET equations (Priestley and Taylor 1972) that rely on the calculation of solar radiation using slope, aspect, topographic shading, and atmospheric transmissivity parameters. The soil storage component of the model uses soil properties to calculate how much soil moisture is available for plant evapotranspiration.

Soil data was assembled only for the six focal areas. To calculate CWD using the BCM, soil porosity, water content at field capacity and wilting point, and soil depth are used. A compilation of regional and national soils data with soil texture, depth, and matrix bulk density from Imbach et al. (2010) were used to estimate soil hydraulic properties within the six modeling sites.

\subsection{Adaptation strategies}

Two main adaptation strategies for native forest pollinators are conservation of forests that can serve as sources of pollinator recolonization following climate events, and restoration of forests where increasing forest cover will increase pollinator services. These strategies are valid for all production systems, but may be particularly valuable for smallholder farmers. We define each strategy below and describe the methods used to identify areas suitable for each.

Restoration is expected to improve pollination services where forest cover is too low to support optimal pollinator densities. Bees and other native pollinators need natural forest habitat for breeding and supplemental foraging (Garibaldi et al. 2013). Below a certain threshold of native habitat cover, pollinator services decline (Kremen et al. 2004). At very low native habitat cover, native pollinators cannot survive or cannot reach crops within their foraging distance and pollinator services cease (Kremen et al. 2007). 
Reservoirs of pollinators can be important in providing sources of recolonization when pollinators are eliminated from forest fragments in agricultural landscapes, especially because of drought. Little is known about optimal configurations of reservoir areas, but larger reservoir areas can be assumed to be better and several dispersed reservoirs can be assumed to be better than a single large reservoir (Keitt 2009).

For the purposes of this study, restoration areas were defined as locations in which natural habitat cover is below 40\% within a 2.4-km radius (Kremen et al. 2004). Forest cover was derived from the 30-m global Landsat database (Hansen et al. 2013), with cell values grouped into $10 \%$ intervals reflecting amount of natural habitat (forest) in the 2.4-km moving window. Increasing forest cover in these areas is expected to increase bee pollination services, while above $40 \%$ natural habitat, no further increment in bee pollination is observed (Kremen et al. 2004). Under future bee diversity, improved forest integrity will help maintain diversity or slow declines due to climate change. Areas of lower forest health in the reforestation areas are identified using declining CWD. Reforestation with drought-tolerant species is advisable for adaptation in these areas.

Reservoir areas were identified based on high future pollinator diversity and high present and future forest integrity. For the purposes of this study, high pollinator diversity is defined as the upper quartile of simulated pollinator diversity for the site, or the area with $>20$ species, whichever is larger. High forest integrity is defined as current forest cover $>90 \%$ or forest cover of $40-90 \%$ and no decline in future CWD of the dry season.

\section{Results}

\subsection{Pollinator diversity}

Bee diversity declines with climate change at three of the six sites, while three sites show a mix of declining and increasing diversity (Fig. 1a-f). Guatemala West and the two Costa Rica sites see some increases in bee diversity with climate change. These increases are most significant in Guatemala West, where moderate (10-20 species) diversity transitions to high ( $>20$ species) diversity in some parts of the site. In the Costa Rica sites, the increases are of 1-2 species in already diverse ( $>20$ species) parts of the sites.

Current bee diversity is generally least in the northern sites and highest in the Costa Rica sites, possibly following the gradient in forest cover. Honduras South and Guatemala East are both highly heterogeneous, with areas of both very high and very low pollinator diversity under current climate.

Under climate change, there is a general reduction in bee richness in the Guatemala East and two Honduras sites. Low diversity $(<5$ species $)$ areas expand and moderate (>10 species) and high diversity (>20 species) areas contract. This results in maintenance of the present gradient in richness, but with some locations that are suitable for native bees under current climate having no suitability for any species in the future, and some locations shifting from high richness to low or medium richness.

In Guatemala West under climate change, moderate heterogeneity becomes more pronounced, with moderate diversity parts of the site becoming both less and more diverse. The two Costa Rica sites show small positive and negative changes in bee diversity with climate 


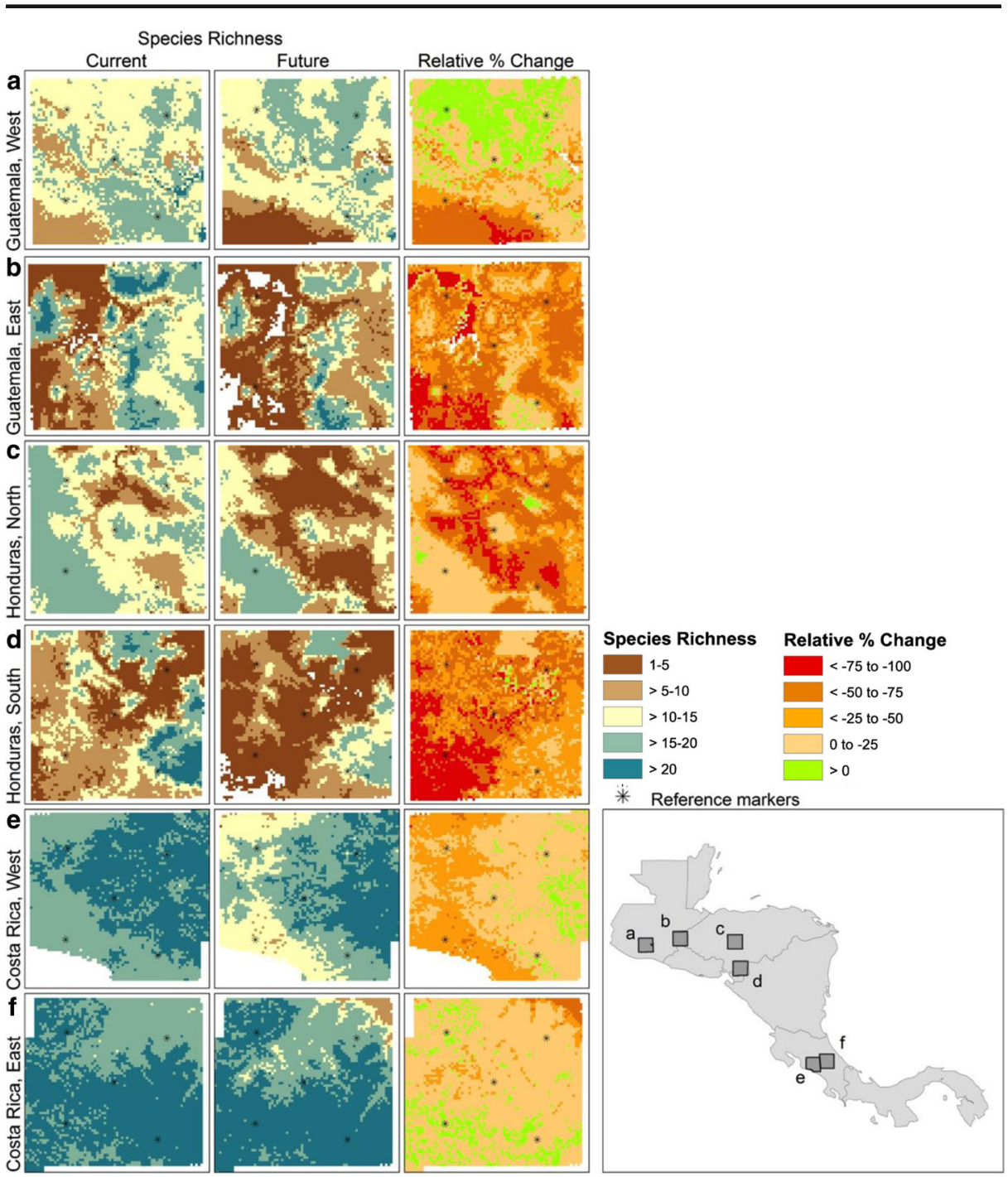

Fig. 1 a-f Current bee diversity (left) and future bee diversity (center) in 2050 climate scenario across the six study sites. Model agreement among six GCMs is shown for species richness and relative percent change in the future scenarios for $80 \%$ model agreement

change, but from relatively high current diversity, so these changes are probably not important to pollination services.

In general, sites with less forest cover and greater warming (northern sites) lose more diversity, while sites with greatest forest cover and less warming (southern sites) retain diversity. These interacting forces play out across the climate change and forest cover gradients of the region. Costa Rica sites have the greatest forest cover and retain the most pollinators, given relatively muted warming compared to the rest of the region. Sites in Guatemala and Honduras have greater warming, less forest, and experience relatively larger losses of pollinator diversity. Because there is disagreement in sign of precipitation change among GCMs, these changes are stronger at lower levels of GCM agreement (50\% model agreement). 


\subsection{Forest health}

Forest health change is approximated by change in dry season climatic water deficit (CWD). CWD is driven by fine-scale variations in moisture availability associated with local soils interacting with changes in climate. The general trend in CWD is negative, driven by increasing temperatures interacting with low rainfall in the dry season (Figure S1a-f).

Few areas in any of the study sites have future dry season CWD that exceeds $25 \mathrm{~mm}$, indicating that the likelihood of widespread tree mortality is low in the sites examined. However, substantial areas across the six study sites have future dry season CWD that exceeds $80 \%$ of the $25-\mathrm{mm}$ value that has been used in the literature to indicate likely large scale tree mortality. This indicates simulated declines in forest health due to climate change, likely sufficient to cause limited mortality of mature trees.

The trend in future CWD generally follows the forest and moisture gradient across the region. The drier and less forested sites in Guatemala and Honduras show increasing dry season CWD in almost all forested areas of each site. The Costa Rica sites show the least proportion of current forest with increasing CWD. The Costa Rica sites also have the largest areas of forest experiencing CWD declines. Outside of Costa Rica, only the Guatemala West site has any forest area in which dry season CWD does not decline.

\subsection{Adaptation strategies}

For adaptation planning, each site can be divided into three zones for adaptation action (Fig. 2a-f), based on coarse-scale climatic controls on bee diversity and current forest cover: (1) high future bee diversity (>20 species) and high forest cover (>90\%) zones are potential reservoirs of pollinators, (2) high future bee diversity and between 90 and $40 \%$ forest cover are areas in which there is potential to restore forest to create pollinator reservoirs, and (3) areas with $10-40 \%$ forest cover, in which restoring forest will increase pollination services. Each of these three zones may be targeted for specific adaptation actions (e.g., restoration with drought-tolerant species) based on fine-scale climate controls on the quality of bee habitat.

High diversity, high forest cover reservoirs (blue in Fig. 2a-f, right panel), areas that retain forest health with climate change (stable or decreasing CWD), are the highest priority for conservation, because they are the most likely to provide healthy pollinator habitat in the future. These areas retain high bee diversity with climate change, serving as sources of recolonization of surrounding forests after droughts or other climate shocks. Areas within this zone with habitat health that is likely to be retained as climate changes are good candidates for protection or, where already protected, zoning for uses compatible with forest integrity.

High diversity, moderate forest cover (40-90\%) areas require restoration to serve as reservoirs. The expense of restoring these areas will only be justified where high forest cover reservoir areas are sparse or unevenly distributed in the landscape, because restoration is almost always more costly than conserving standing forest (Busch et al. 2012). Where paying the cost of restoration is justified, areas with high forest health under climate change should be prioritized (included in reservoir protection areas, Fig. 2a-f), and areas of declining forest health under future climate change avoided, to help ensure that restored forests will endure in the future.

Finally, in the 10-40\% forest cover zone (forest restoration areas in Fig. 2a-f, right panel), restoring forest is expected to increase pollinator services (Kremen et al. 2004). In this zone as well, forests that retain health as climate changes are priority for restoration (green in Fig. $2 \mathrm{a}-\mathrm{f}$, 


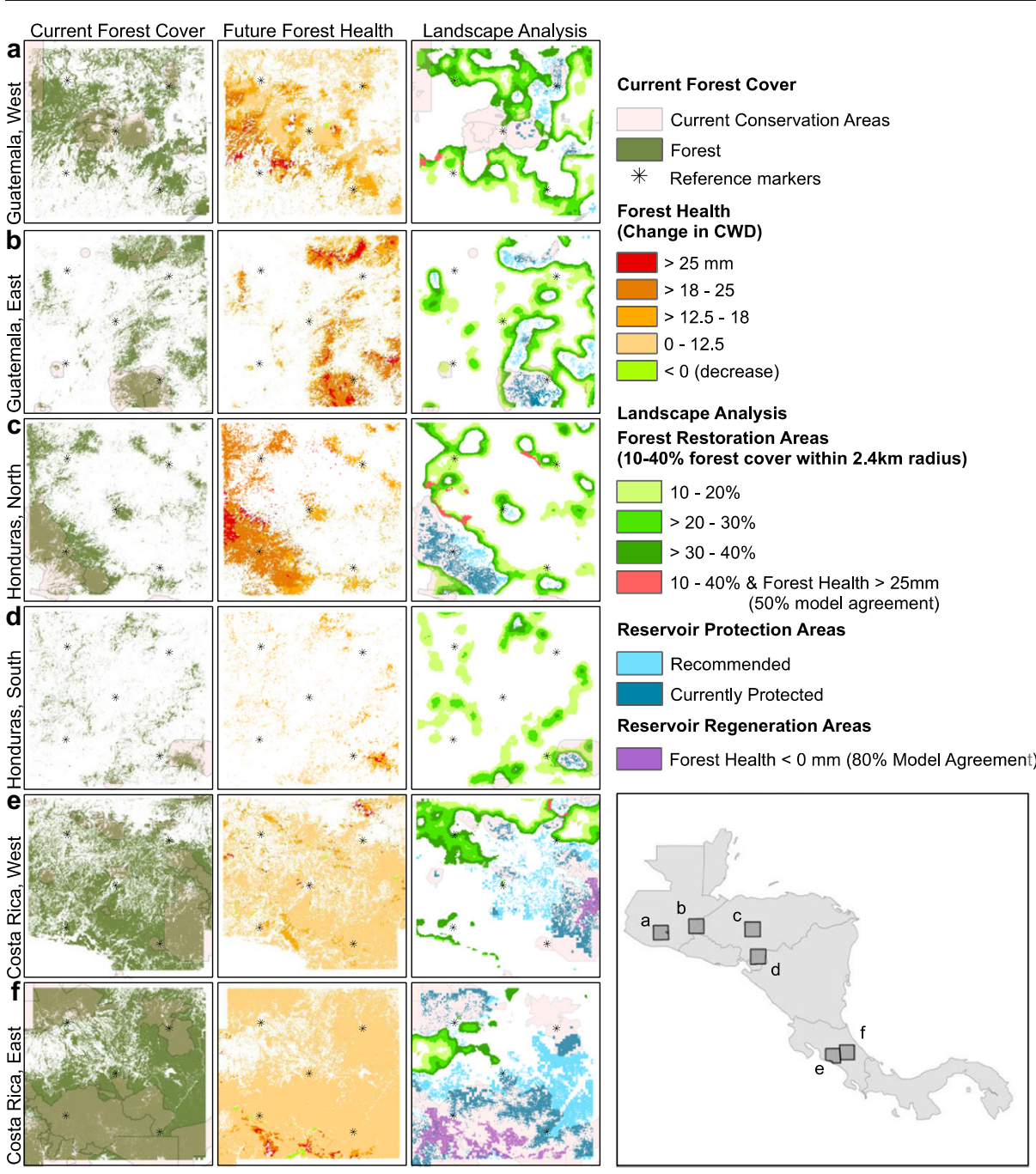

Fig. 2 a-f Forest cover, forest health, and landscape adaptation planning. For each of the six study sites, current forest cover (left), projected forest health using CWD (center), and landscape zonation using the principles described in the text (right). Future forest health shows 50\% model agreement among the six GCMs in the 2050 timeframe (center panels in figure). Forest restoration areas, reservoir protection areas, and reservoir regeneration areas are as defined in the text (right panels in figure)

right panel) and areas of declining habitat health (red in Fig. 2a-f, right panel) due to climate change are lower priority or candidates for restoration with drought-tolerant species.

All sites have some potential reservoir areas. Honduras South has the least potential reservoir area, while the Costa Rica sites showed the most. Most reservoir areas were within existing protected areas, underscoring the value of protected areas in conserving forest and maintaining pollinator services as well as other ecosystem services. Both Guatemala and both Honduras sites show low to moderate area of potential reservoir and some non-protected potential reservoir forests. The Costa Rica sites had large areas of potential reservoir and large areas of protected reservoir. The Costa Rica sites have better distribution of protected reservoir within the sites. 
Restoration areas were limited in the Costa Rica sites due to large areas of relatively intact forest cover, while all other sites had large areas of fragmented forest suitable for restoration. Areas of high future forest health in the 40-90\% zone, candidates for restoration to create reservoirs, were only significant in the Costa Rica sites where there were already abundant reservoirs.

\section{Discussion}

Designing adaptation strategies is a site-specific process that can be informed by both coarseand fine-scale modeling. We have demonstrated several modeling-supported adaptation strategies for pollination services at six sites in Central America. The cost of modeling can be substantial and needs to be built into estimates of the cost of adaptation (Hannah et al. 2016). At the same time, less expensive surrogates may be used to reduce costs. For example, where financial resources are not available for modeling CWD, field practitioners might use soil water holding capacity to identify areas at risk from or likely to be resilient to drought.

Climate change and forest cover gradients are in opposition across the region. High climate change areas are generally low forest cover areas and vice versa. This poses a particular challenge for the cultivation of coffee and other crops that benefit from native forest pollinators. Low forest cover is often associated with high fragmentation, and forest fragments will be especially prone to drying as climate changes (Gascon et al. 2000). The areas most exposed to climate change therefore have the least adaptive capacity associated with forest cover. Restoration may be a key to building adaptive capacity in these areas.

Reservoir areas can aid adaptation in areas of relatively high forest cover by providing sources of recolonization of native forest pollinators following climatic shocks. Forested areas that harbor the greatest diversity of native forest pollinators may be expected to be the most valuable reservoir areas. This is a concept that can be applied at multiple scales. We have illustrated application at landscape-scale study sites, but individual farms could also identify and protect potential forest reservoir areas. Distributing reservoir areas throughout a landscape or farm can be expected to shorten recovery times following drought and other climatic shocks by reducing distances pollinators have to cover to recolonize damaged habitats.

Restoration areas are an adaptation response that allows simultaneous increase in current pollinator services and maintenance of those services as climate changes. The 10-40\% surrounding native habitat criterion used in this study is illustrative, and based on values measured outside the region. Native pollinator services saturate at similar scales in the one study available from the region (Ricketts et al. 2004), so it is likely that tropical forests will provide enhanced pollination services when forest cover is increased above these levels. The $10-40 \%$ thresholds may be pragmatic interim values to use until more measured values for Central American forests become available. Fine scale simulations of forest health using CWD allow prioritizing areas likely to retain healthy forest for restoration, as well as indicating areas of declining forest health where restoration using drought tolerant species is advisable.

Our application of CWD modeling was not validated against field samples, but this could be accomplished (for example, Flint et al. 2013) with limited additional investment. Soils information can be critical in determining CWD values, while soils maps are often unavailable at fine scale in Central America. Combining modeling with field data collection to improve soils information and validate CWD model results would produce a major improvement in adaptation planning in practice. 


\section{Conclusion}

The results of this study illustrate that modeling at multiple scales can help inform adaptation decision-making at the interface of agriculture and ecosystems. Principles of adaptation such as reservoir areas and restoration areas for pollinator services are needed for other regions, other sectors, and other adaptation issues. Where precise understanding of existing landscape interactions such as crop-pollinator-habitat relationships is lacking, the best course of action may be developing testable adaptation principles and applying them in an adaptive management framework that can be informed by modeling and on-the-ground monitoring.

Current landscape management initiatives in Central America have not fully integrated climate change, and much climate change adaptation planning is not yet integrated across sectors. For example, biological corridors initiatives such as Paseo Pantera have attempted to harmonize human and wildlife land uses (Kaiser 2001), but those plans have not fully considered the effects of climate change on humans and wildlife. In the agricultural sector, the importance of climate change in mediating outbreaks of coffee leaf rust is increasingly well-recognized, but moving from reactive planning to limit leaf rust and maintain yields is not yet balanced by proactive integrated planning of farms and forests at the landscape scale. Modeling at multiple scales can play in important role in the transition from reactive to proactive landscape planning for climate change.

Acknowledgments This study was conducted as part of the CASCADE project ("Ecosystem-based Adaptation for Smallholder Subsistence and Coffee Farming Communities in Central America"). This project is part of the International Climate Initiative (ICI). The German Federal Ministry for the Environment, Nature Conservation, Building and Nuclear Safety (BMUB) supports this initiative on the basis of a decision adopted by the German Bundestag. We thank the Betty and Gordon Moore Center for Science at Conservation International for providing funds for open access.

Open Access This article is distributed under the terms of the Creative Commons Attribution 4.0 International License (http://creativecommons.org/licenses/by/4.0/), which permits unrestricted use, distribution, and reproduction in any medium, provided you give appropriate credit to the original author(s) and the source, provide a link to the Creative Commons license, and indicate if changes were made.

\section{References}

Ackerly DD, Cornwell WK, Weiss SB, Flint LE, Flint AL(2015) A geographic mosaic of climate change impacts on terrestrial vegetation: which areas are most at risk? PLoS ONE 10(6):e0130629

AMNH (American Museum of Natural History) (2013) Bee Database Project. Available at: http://www.amnh. org/our-research/invertebrate-zoology/resources/collections-databases/bee-database-project

Berdegué JA, Fuentealba R (2011) Latin America: the state of smallholders in agriculture. Conference on new directions for smallholder agriculture. International Fund for Agricultural Development, Rome

Busch J, Dave R, Hannah LE, Cameron A, Rasolohery A, Roehrdanz P, Schatz G (2012) Climate change and the cost of conserving species in Madagascar. Conserv Biol 26(3):408-419

Condit R, Hubbell SP, Foster RB (1995) Mortality rates of 205 neotropical tree and shrub species and the impact of a severe drought. Ecol Monogr 65(4):419-439

FAO (Food and Agriculture Organization of the United Nations) (2015) FAO statistical pocketbook: coffee 2015. Rome. Available at: http://www.fao.org/3/ai4985e.pdf

Flint LE, Flint AL (2012) Downscaling climate change scenarios for ecologic applications. Ecol Process 1:1

Flint LE, Flint AL, Thorne JH, Boynton R (2013) Fine-scale hydrologic modeling for regional landscape applications: the California basin characterization model development and performance. Ecol Process 2(1):1

Flint LE, Flint AL, Thorne JH (2015) Climate change: evaluating your local and regional water resources: U.S. Geological Survey Fact Sheet 2014-3098 
Garibaldi LA, Steffan-Dewenter I, Kremen C, Morales JM, Bommarco R, Cunningham SA, Klein AM (2011) Stability of pollination services decreases with isolation from natural areas despite honey bee visits. Ecol Lett 14(10):1062-1072

Garibaldi LA, Steffan-Dewenter I, Winfree R, Aizen MA, Bommarco R, Cunningham SA, Klein AM (2013) Wild pollinators enhance fruit set of crops regardless of honey bee abundance. Science 339(6127):1608-1611

Garibaldi LA, Carvalheiro LG, Leonhardt SD, Aizen MA, Blaauw BR, Isaacs R, Kuhlmann M, Kleijn D, Klein AM, Kremen C, Morandin L (2014) From research to action: enhancing crop yield through wild pollinators. Front Ecol Environ 12(8):439-447

Gascon C, Williamson GB, da Fonseca GA (2000) Receding forest edges and vanishing reserves. Science 288(5470):1356-1358

GBIF (Global Biodiversity Information Facility) (2001) Global biodiversity species database. Available at: http://data.gbif.org/occurrences/ Accessed 8 Nov 2014

Hannah L, Roehrdanz PR, Ikegami M, Shepard AV, Shaw MR, Tabor G, Hijmans RJ (2013) Climate change, wine, and conservation. Proc Natl Acad Sci 110(17):6907-6912

Hannah L, Donatti CI, Harvey CA, AlfaroE, Rodrigues DA, Bouroncle C, Castellanos E, Diaz F, Fung E, Hidalgo HG, Imbach P, Läderach P, Landrum JP, Solano AL (2016) Regional modeling of climate change impacts on smallholder agriculture ecosystems in Central America. Climatic Change (this issue)

Hansen MC, Potapov PV, Moore R, Hancher M, Turubanova SA, Tyukavina A, Townshend JRG (2013) Highresolution global maps of 21st-century forest cover change. Science 342(6160):850-853

Hanson RT, Flint LE, Flint AL, Dettinger MD, Faunt CC, Cayan D, Schmid W (2012) A method for physically based model analysis of conjunctive use in response to potential climate changes. Water Resour Res 48: W00L08. doi:10.1029/2011WR010774

Hijmans RJ, Cameron SE, Parra JL, Jones PG, Jarvis A (2005) Very high resolution interpolated climate surfaces for global land areas. Int J Climatol 25:1965-1978

Imbach P, Molina L, Locatelli B, Roupsard O, Ciais P, Corrales L, Mahe G (2010) Climatology-based regional modelling of potential vegetation and average annual long-term runoff for Mesoamerica. Hydrol Earth Syst Sci 14:1801-1817. doi:10.5194/hess-14-1801-2010

INBio (Instituto Nacional de Biodiversidad, Costa Rica) (2001) Atta, base de datos de especímenes del INBio. Available at: http://atta.inbio.ac.cr/

Kaiser J (2001) Bold corridor project confronts political reality. Science 293(5538):2196-2199

Keitt TH (2009) Habitat conversion, extinction thresholds, and pollination services in agroecosystems. Ecol Appl 19(6):1561-1573

Kennedy CM, Lonsdorf E, Neel MC, Williams NM, Ricketts TH, Winfree R, Bommarco R, Brittain C, Burley AL, Cariveau D, Carvalheiro LG (2013) A global quantitative synthesis of local and landscape effects on wild bee pollinators in agroecosystems. Ecol Lett 16(5):584-599

Klein AM, Vaissiere BE, Cane JH, Steffan-Dewenter I, Cunningham SA, Kremen C, Tscharntke T (2007) Importance of pollinators in changing landscapes for world crops. Proc R Soc Lond B Biol Sci 274(1608):303-313

Koh I, Lonsdorf EV, Williams NM, Brittain C, Isaacs R, Gibbs J, Ricketts TH (2016) Modeling the status, trends, and impacts of wild bee abundance in the United States. Proc Natl Acad Sci 113(1):140-145

Kremen C, Williams NM, Bugg RL, Fay JP, Thorp RW (2004) The area requirements of an ecosystem service: crop pollination by native bee communities in California. Ecol Lett 7(11):1109-1119

Kremen C, Williams NM, Aizen MA, Gemmill-Herren B, LeBuhn G, Minckley R, Ricketts TH (2007) Pollination and other ecosystem services produced by mobile organisms: a conceptual framework for the effects of land-use change. Ecol Lett 10(4):299-314

Lewis SJ, Brando PM, Phillips OL, van der Heijden GMF, Nepstad D (2011) The 2010 Amazon drought. Science 331(6017):554

McIntyre PJ, Thorne JH, Dolanc CR, Flint AL, Flint LE, Kelly M, Ackerly DD (2015) 20th century shifts in forest structure in California: denser forests, smaller trees, and increased dominance of oaks. Proc Natl Acad Sci 112(5):1458-1463

Memmott J, Craze PG, Waser NM, Price MV (2007) Global warming and the disruption of plant-pollinator interactions. Ecol Lett 10(8):710-717

Parmesan C, Yohe G (2003) A globally coherent fingerprint of climate change impacts across natural systems. Nature 421(6918):37-42

Pearson RG, Dawson TP (2003) Predicting the impacts of climate change on the distribution of species: are bioclimate envelope models useful? Glob Ecol Biogeogr 12(5):361-371

Phillips SJ, Anderson RP, Schapire RE (2006) Maximum entropy modeling of species geographic distributions. Ecol Model 190:231-259

Potts SG, Biesmeijer JC, Kremen C, Neumann P, Schweiger O, Kunin WE (2010) Global pollinator declines: trends, impacts and drivers. Trends Ecol Evol 25(6):345-353 
Priestley CHB, Taylor RJ (1972) On the assessment of surface heat flux and evaporation using large-scale parameters. Mon Weather Rev 100(2):81-92

Ricketts TH (2004) Tropical forest fragments enhance pollinator activity in nearby coffee crops. Conserv Biol 18: 1262-1271

Ricketts TH, Daily GC, Ehrlich PR, Michener CD (2004) Economic value of tropical forest to coffee production. Proc Natl Acad Sci U S A 101(34):12579-12582

Ricketts TH, Regetz J, Steffan-Dewenter I, Cunningham SA, Kremen C, Bogdanski A, Viana BF (2008) Landscape effects on crop pollination services: are there general patterns? Ecol Lett 11(5):499-515

Root TL, Price JT, Hall KR, Schneider SH, Rosenzweig C, Pounds JA (2003) Fingerprints of global warming on wild animals and plants. Nature 421(6918):57-60

Rosenzweig C, Parry ML (1994) Potential impact of climate change on world food supply. Nature 367(6459): $133-138$

Stephenson N (1998) Actual evapotranspiration and deficit: biologically meaningful correlates of vegetation distribution across spatial scales. J Biogeogr 25(5):855-870

Turner WR, Bradley BA, Estes LD, Hole DG, Oppenheimer M, Wilcove DS (2010) Climate change: helping nature survive the human response. Conserv Lett 3(5):304-312

Underwood EC, Olson D, Hollander AD, Quinn JF (2014) Ever-wet tropical forests as biodiversity refuges. Nat Clim Chang 4(9):740-741 